\title{
Severity distribution of Alzheimer's disease dementia and mild cognitive impairment in the Framingham Heart Study
}

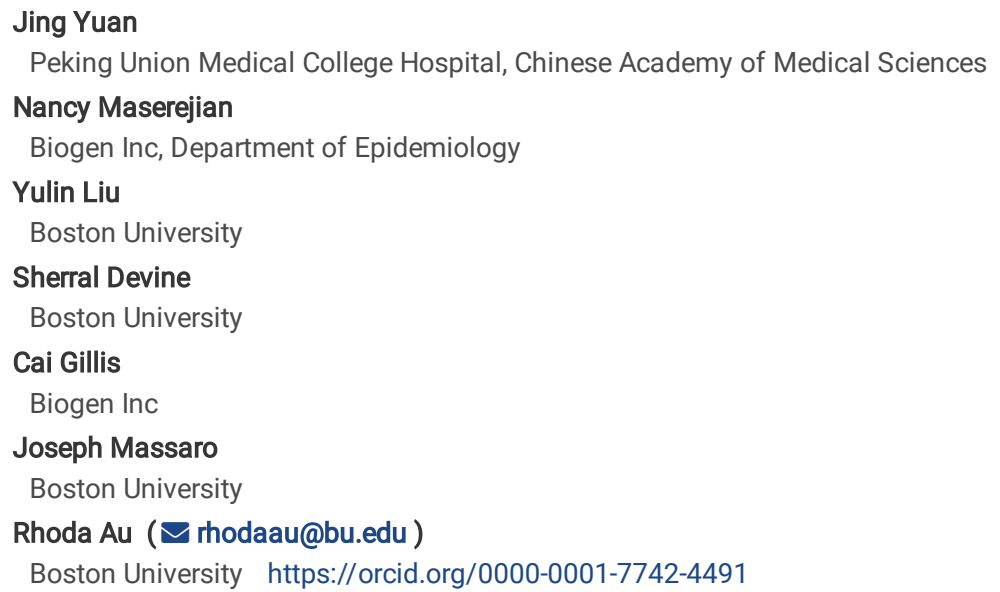

Version of Record: A version of this preprint was published at Journal of Alzheimer's Disease on January 19th, 2021. See the published version at https://doi.org/10.3233/JAD-200786. 


\section{Abstract}

Background: Studies providing Alzheimer's disease (AD) prevalence data have largely neglected to characterize the proportion of AD that is mild, moderate or severe. Estimates of the severity distribution along the AD continuum, including the mild cognitive impairment ( $\mathrm{MCl})$ stage, are important to plan research and allocate future resources, particularly resources targeted at particular stages of disease.

Methods: Participants (aged 50-94) with prevalent MCl or AD dementia clinical syndrome were cross-sectionally selected from three time-windows of the population-based Framingham Heart Study in 2004-2005 ( $n=381), 2006-2007$ ( $n=422)$, and 2008-2009 ( $n=389)$. Summary estimates of the severity distribution were achieved by pooling results across time-windows. Diagnosis and severity were assessed by consensus dementia review. MCl-progressive was determined if the participant had documented progression to AD dementia clinical syndrome using longitudinal data.

Results: Among AD dementia participants, the pooled percentages were $50.4 \%$ for mild, $30.3 \%$ for moderate, and $19.3 \%$ for severe. Among all $\mathrm{MCl}$ and $\mathrm{AD}$ participants, the pooled percentages were $29.5 \%, 19.6 \%, 25.7 \%$, and $45.2 \%$ for $\mathrm{MCl}$-not-progressive, MCl-progressive, mild AD dementia, and the combined group of $\mathrm{MCl}$-progressive \& mild $\mathrm{AD}$ dementia, respectively. Distributions by age and sex were presented.

Conclusions: Heterogeneity in severity of the AD population exists. That half of prevalent cases have mild disease underscores the need for research and interventions to slow decline of this burdensome disease.

Limitations: First, the FHS cohort participants were almost homogenously Caucasians and residents of a single city in MA, that limits the generalization of the results. Second, although FHS is a longitudinal study, the study population over the three time-windows would not be expected to be as dynamic as that of sampling participants from different geographic areas. Lastly, the study lacked AD biomarker confirmation (e.g., amyloid, tau, neurodegeneration), which would have increased the accuracy of case ascertainment.

\section{Introduction}

Alzheimer's disease (AD) has been conceptualized as a pathological-clinical continuum[1]. Although it is challenging to identify clear transitional points, the disease begins with a long asymptomatic period during which pathophysiological processes are progressing (preclinical stage)[1], then evolves to the symptomatic mild cognitive impairment ( $\mathrm{MCl}$ ) phase[2], and finally advances to the dementia phase with increasing stages of severity impairment[3]. Estimates of the disease severity distribution of the symptomatic stages ( $\mathrm{MCl}$ and dementia) of Alzheimer's clinical syndrome are useful for health services planning and the development of new disease-modifying therapies that target different stages of the disease.

Population-based research on the percentage of prevalent AD dementia that is mild, moderate, or severe is limited, with only one previous epidemiological study available. The Chicago Health and Aging Project (CHAP) $[4](n=6,153)$ estimated the sample-weighted distribution of severity of $A D$ dementia clinical syndrome (hereafter referred to as AD dementia), classified by Mini-Mental State Examination (MMSE), using data collected from 1994-1996[5]. Results were that $48 \%$ of prevalent AD dementia cases were mild, $31 \%$ were moderate, and $21 \%$ were severe. The percentages with severe AD dementia increased by age group: among persons aged $65-74$ y, $17 \%$ were severe compared to $20 \%$ among persons aged $75-84$ y and $28 \%$ among those aged $85+y$.

Apart from the CHAP study, other prior research was conducted for dementia in general, rather than AD dementia specifically. For example, the Dementia U.K. 2007 report considered data from the 1980s and provided an expert consensus that that among people with late-onset dementia, 55.4\% had mild dementia, $32.1 \%$ had moderate dementia, and $12.5 \%$ had severe dementia[6]. This distribution was not altered in their 2014 update owing to no new data on severity[7].

More recent data on $A D$ dementia, specifically across all severity stages from $\mathrm{MCl}$ to severe, would be useful for determining study design for research and drug development. Furthermore, data on severity by age and sex has not been widely reported from epidemiologic studies. Hence, this paper aims to characterize the distribution of severity of $\mathrm{AD}$ dementia and $\mathrm{MCl}$ among prevalent cases in the population-based Framingham Heart Study (FHS). Rather than a single time point, we analysed data from three cross-sectional time-windows in 2004-2005, 2006-2007, and 2008-2009, which allowed us to then pool results to achieve more robust estimates, overall and within age and sex category.

\section{Methods Cohort profile}

The FHS, a community-based, multigenerational, prospective cohort study, was established in 1948 in the town of Framingham, Massachusetts. Details about the study profile are available[8, 9]. Briefly, FHS cohorts include the Original Cohort $(n=5209)$, the Offspring Cohort $(n=5124)$, the Third Generation $(n=4209)$, the Omni1 $(n=500)$, the Omni2 $(n=410)$, and the New Offspring Spouses $(n=103)$ under regular follow-up[8, 10].

\section{Assessment and ascertainment of cognitive status}

Brain aging research began at FHS in 1976, and the detailed cognitive evaluation methods, case ascertainment procedure, and quality control approaches for FHS have been published[11, 12]. Briefly, participants were followed-up approximately every two years in the Original cohort and on average every four years in other cohorts. Dementia reviews were routinely conducted by a panel of at least one neurologist and one neuropsychologist with all available data including comprehensive neuropsychological test (NP) results, neurological examination, family interview, FHS health exam records, and/or hospital/nursing home medical records. Those who were flagged for possible cognitive impairment were prioritized for review. All deceased participants were reviewed to determine final cognitive status at time of death regardless of cognitive status. A diagnosis of $\mathrm{MCl}$ required evidence of a decline in cognitive performance in one or more cognitive domains, no records indicating functional decline, and not meeting criteria for dementia[2].The diagnosis of AD dementia satisfied the DSM-IV 
criteria for dementia[13] and the criteria of National Institute of Neurological and Communicative Disorders and Stroke and the Alzheimer's Disease and Related Disorders Association (NINCDS-ADRDA) for probable AD[14]. The presence of vascular dementia did not disqualify a concurrent diagnosis of AD, if indicated. The severity of dementia and diagnosis of $\mathrm{MCl}$ was determined by the review panel using clinical judgment. Although the Clinical Dementia Rating (CDR) scale[15] was not formally applied, the neurologist and neuropsychologist used CDR parameters as part of the severity judgment process. For example, an individual progresses into the mild dementia stage when they are no longer able to perform some activities of daily living (ADL) with assistance and their cognitive impairment becomes increasingly obvious to others (e.g., repeats self, forget what was just said, makes mistakes at work). A person in the moderate stage shows a more significant cognitive impairment, and symptoms include things like requiring help with ADLs, disorientation to time and/or place, forgetting personal history, demonstrating a notable change in personality or behavior, etc. In the severe stage, the individual needs complete assistance with ADLs, they may not recognize family members, they may have limited or no speech, they may be doubly incontinent, they may not be able to walk/sit/swallow, etc. The determination of whether $\mathrm{MCl}$ later progressed to AD dementia was based on the observed follow-up. That is, it was determined if the participant had documented progression to $A D$ dementia clinical syndrome using longitudinal data. Participants with $\mathrm{MCl}$ who progressed to $\mathrm{AD}$ dementia during follow-up are abbreviated as 'MCl-progressive', and those who did not progress during the examined time frames are abbreviated as 'MCl-not-progressive' hereafter. The median length of follow-up of all MCl cases was 5.0-5.3 y (interquartile range [IQR] 2.9-8.7 y) across Windows (e.g., Window 1 median 5.0, IQR 2.9-8.7 y). Median follow-up was longer among $\mathrm{MCl}$ cases who did not progress to AD dementia (median 6.2, IQR 4.1-10.9 y), indicating sufficient time to capture progression should they occur[16].

\section{Samples selection of prevalent $\mathrm{MCl}$ and $\mathrm{AD}$ dementia cases}

Prevalent $\mathrm{MCl}$ and $\mathrm{AD}$ dementia cases were cross-sectionally selected in three different time-windows of the years 2004-2005 (Window 1), 2006-2007 (Window 2), and 2008-2009 (Window 3). As shown in Fig. 1a-1c for each window in detail, the sample were selected by three steps: (1) select all participants aged 50-94 y in each window; (2) select cognitive status reviewed owing to flag present for possible cognitive impairment (see prior section); (3) exclude those without assessment of cognitive status or disease severity at any time during study participation and those not being assigned as $\mathrm{MCl}$ or $\mathrm{AD}$ dementia during or before the window. After the three steps, the numbers of prevalent $\mathrm{MCl}$ or AD dementia were $\mathrm{N}=381, \mathrm{~N}=422$, and $\mathrm{N}=389$ cases for Windows $1-3$, respectively. When severity status in a specific window was missing, we assigned severity based on the median transition times observed among participants with data in the FHS dementia review database: 2.3 years for $\mathrm{MCl}$ to mild (observed data of 991 participants); 2.2 years for mild to moderate (observed data of 772 participants); and 1.9 years for moderate to severe (observed data of 463 participants). Among the aforementioned prevalent cases, severity status was assigned in this manner for $n=61$ in Window $1, n=65$ in Window 2, and $n=60$ in Window 3.

\section{Statistical Analysis}

Analyses were first conducted in each time-window separately. For each window, we examined the following case groups: AD dementia (overall and by severity), $\mathrm{MCl}$ (overall and by progression), a combined group of $\mathrm{MCl}$-progressive \& $\mathrm{AD}$ dementia, and a combined group of $\mathrm{MCl}$-progressive \& mild $\mathrm{AD}$ dementia. This latter group of $\mathrm{MCl}$-progressive and mild AD dementia are of interest owing to current research on potential disease modifying therapies for earlier stages of AD. We calculated descriptive statistics for age, sex, educational level, and apolipoprotein-E $\varepsilon 4$ allele carrying status (ApoE $\varepsilon 4-$, ApoE $\varepsilon 4+)$. Among participants with $A D$ dementia, the number and percentages of participants with each severity level (mild, moderate, and severe) are presented by age (50.0-64.9; 65.0-74.9; 75.0-84.9; over 85.0) and by sex within each time-window. Among participants with MCl or AD dementia (total sample), the number and row percentages of participants who were $\mathrm{MCl}$ progressive, $\mathrm{MCl}$-not-progressive, mild $\mathrm{AD}$ dementia, and combined group of $\mathrm{MCl}$-progressive \& mild $\mathrm{AD}$ dementia are presented by each age group and by sex within each time-window.

To calculate summary estimates across all time-windows, we used predicted values from generalized estimating equation (GEE) multinomial regression models with a cumulative logit link, separately for each age group and sex. This method accounted for the three time-windows not being mutually exclusive with respect to participants (overlap: $N=293$ cases in Window 1 \& $2 ; N=197$ cases in Window 1 \& $3 ; N=317$ cases in Window 2 \& $3 ; N=197$ cases in Window $1,2, \& 3)$; traditional meta-analysis methods do not take into account participant overlap. The models were intercept-only models, with the dependent variables being severity (mild, moderate, severe), separate $\mathrm{MCl} / \mathrm{AD}$ status ( $\mathrm{MCl}$-progressive, $\mathrm{MCl}$-not-progressive, mild $\mathrm{AD}$ dementia), or combined $\mathrm{MCl} / \mathrm{AD}$ status ( $\mathrm{MCl}$ progressive \& mild $A D$ dementia, neither mild $A D$ dementia nor $\mathrm{MCl}$-progressive; for this latter outcome the multinomial regression model defaults to a binomial logistic regression model), and participant as a random effect. Since multinomial regression GEE models can only assume an independent withinparticipant correlation structure, the robust estimate of percentages and their two-sided confidence intervals (Cl)are presented here. These robust estimates are theoretically appropriate, even if the within-participant correlation structure is mis-specified. Statistical analyses were conducted using SAS Version 9.4.

\section{Results}

Demographic characteristics and ApoE $\varepsilon 4$ status of the samples for each time-window are shown in Table 1 and Tables A.1-A.2. Compared to participants with $\mathrm{MCl}$, those with $A D$ dementia were older in each window (e.g., Window 1: mean age AD $85.1 \mathrm{y} ; \mathrm{MCl} 81.5 \mathrm{y}$ ). Among participants with $\mathrm{MCl}$, $\mathrm{MCl}$-progressive was slightly older than $\mathrm{MCl}$-not-progressive (e.g., Window 1: mean age $\mathrm{MCl}$-progressive $82.8 \mathrm{y}$; MCl-not-progressive $80.2 \mathrm{y}$ ). There were more females than males in the samples of $A D$ dementia (69.4\%-70.9\% female), $\mathrm{MCl}$ (54.5\%-58.8\% female), and MCl-progressive (63.9\%-70.2\% female), whereas the $\mathrm{MCl}$-notprogressive was more balanced by sex. Across all three windows, $32.1 \%-39.0 \%$ of participants with AD dementia and $39.6 \%-42.7 \%$ of $\mathrm{MCl}$ received $>12 \mathrm{y}$ of education. ApoE $\varepsilon 4$ positivity ranged from $26.3 \%-31.3 \%$ in the three windows among AD dementia and from $21.3 \%-28.2 \%$ among $\mathrm{MCl}$ participants. 
Table 1

Demographics and ApoE 4 status by window

\begin{tabular}{|c|c|c|c|c|c|c|c|c|c|c|c|c|c|c|c|c|}
\hline & \multicolumn{6}{|c|}{ AD dementia } & \multicolumn{6}{|l|}{$\mathrm{MCl}$} & \multicolumn{4}{|c|}{ MCI-not-progressive } \\
\hline & W 1 & & W 2 & & W 3 & & W 1 & & W 2 & & W 3 & & W 1 & & W 2 & \\
\hline$n$ & 216 & & 209 & & 182 & & 165 & & 213 & & 207 & & 81 & & 130 & \\
\hline $\begin{array}{l}\text { Age, mean } \\
\text { (sd) }\end{array}$ & 85.1 & $(7.0)$ & 85.4 & $(7.2)$ & 85.4 & $(6.6)$ & 81.5 & (8.1) & 80.0 & $(8.1)$ & 81.2 & (8.3) & 80.2 & (9.1) & 79.6 & (8.5) \\
\hline \multicolumn{17}{|l|}{ Sex, n (\%) } \\
\hline Male & 65 & (30.1) & 64 & $(30.6)$ & 53 & $(29.1)$ & 68 & $(41.2)$ & 97 & $(45.5)$ & 88 & $(42.5)$ & 43 & $(53.1)$ & 67 & (51.5) \\
\hline Female & 151 & (69.9) & 145 & $(69.4)$ & 129 & (70.9) & 97 & $(58.8)$ & 116 & $(54.5)$ & 119 & $(57.5)$ & 38 & $(46.9)$ & 63 & $(48.5)$ \\
\hline \multicolumn{17}{|l|}{$\begin{array}{l}\text { Education, } \\
\text { n (\%) }\end{array}$} \\
\hline$<=12 y$ & 138 & $(63.9)$ & 130 & $(62.2)$ & 101 & $(55.5)$ & 93 & $(56.4)$ & 120 & $(56.3)$ & 122 & (58.9) & 45 & $(55.6)$ & 75 & (57.7) \\
\hline$>12 y$ & 72 & (33.3) & 67 & (32.1) & 71 & (39.0) & 66 & $(40.0)$ & 91 & $(42.7)$ & 82 & (39.6) & 35 & $(43.2)$ & 54 & (41.5) \\
\hline Missing & 6 & $(2.8)$ & 12 & (5.7) & 10 & $(5.5)$ & 6 & (3.6) & 2 & $(1.0)$ & 3 & (1.5) & 1 & $(1.2)$ & 1 & $(0.8)$ \\
\hline \multicolumn{17}{|l|}{$\begin{array}{l}\text { ApoE } \varepsilon 4 \\
\mathrm{n}(\%)\end{array}$} \\
\hline ApoE $\varepsilon 4+$ & 65 & $(30.1)$ & 55 & $(26.3)$ & 57 & (31.3) & 44 & $(26.7)$ & 60 & $(28.2)$ & 44 & (21.3) & 22 & $(27.2)$ & 30 & (23.1) \\
\hline ApoE $\varepsilon 4-$ & 134 & $(62.0)$ & 132 & $(63.2)$ & 108 & $(59.3)$ & 110 & $(66.7)$ & 143 & $(67.1)$ & 151 & (72.9) & 54 & $(66.7)$ & 92 & (70.8) \\
\hline Missing & 17 & $(7.9)$ & 22 & (10.5) & 17 & (9.3) & 11 & $(6.7)$ & 10 & $(4.7)$ & 12 & (5.8) & 5 & (6.2) & 8 & (6.1) \\
\hline
\end{tabular}

Distribution of AD dementia by disease severity, by age group, and by sex in each time-window and the pooled percentages are presented in Table 2, Fig. 2, and supplementary Figure B.1. Among participants with AD dementia, the percentages of disease in the mild stage were generally higher than those in moderate and severe stages in all three windows. The pooled percentages by disease severity across the three windows combined were $50.4 \%$ for mild, $30.3 \%$ for moderate, and $19.3 \%$ for severe. Sample sizes by age were small thereby providing less robust estimates. In particular, there was a limited number $(n=12-$ 15 cases) of participants with $A D$ dementia under the age of $75 \mathrm{y}$, which precluded obtaining reliable estimates in the first two age groups. Among $A D$ dementia cases age $\geq 75 \mathrm{y}$, the percentage of cases that were in the mild stage appeared higher among those aged 75.0-84.9 $\mathrm{y}$ compared to those aged 85.0 $+y(53.8 \%$ vs. $47.1 \%$ in Window $1 ; 59.4 \%$ vs. $46.9 \%$ in Window $2 ; 62.3 \%$ vs. $41.6 \%$ in Window 3$)$. The pooled percentages of mild, moderate, and severe were $58.6 \%, 22.7 \%$, and $18.7 \%$ in the group aged $75.0-84.9$ y. The corresponding percentages were $45.5 \%, 35.9 \%$, and $18.6 \%$ in the group aged over $85.0 \mathrm{y}$. Stratifying by sex, there was a slightly lower percentage of females in the mild stage than males (pooled estimates: $49.2 \%$ vs. $53.3 \%$ ), similar percentages in the moderate stage (pooled estimates: $30.6 \%$ vs. $29.7 \%$ ), and slightly higher percentages in the severe stage (pooled estimates: $20.2 \%$ vs. $17.0 \%$ ).

Table 2

Percentages of $A D$ dementia by severity, age, and sex in each time-window among AD dementia

\begin{tabular}{|c|c|c|c|c|c|c|c|c|c|c|c|c|c|c|c|c|c|c|}
\hline \multirow[b]{3}{*}{ Overall } & \multicolumn{7}{|c|}{ Window 1 * } & \multicolumn{7}{|c|}{ Window 2 * } & \multicolumn{4}{|c|}{ Window 3 * } \\
\hline & \multirow{2}{*}{$\begin{array}{l}\text { Total } \\
216\end{array}$} & \multicolumn{2}{|l|}{ Mild } & \multicolumn{2}{|c|}{ Moderate } & \multicolumn{2}{|c|}{ Severe } & \multirow{2}{*}{$\begin{array}{l}\text { Total } \\
209\end{array}$} & \multicolumn{2}{|l|}{ Mild } & \multicolumn{2}{|c|}{ Moderate } & \multicolumn{2}{|c|}{ Severe } & \multirow{2}{*}{$\begin{array}{l}\text { Total } \\
182\end{array}$} & \multicolumn{2}{|c|}{ Mild } & \multirow{2}{*}{$\frac{M}{5 i}$} \\
\hline & & 106 & $(49.1)$ & 67 & (31.0) & 43 & (19.9) & & 108 & (51.7) & 60 & $(28.7)$ & 41 & (19.6) & & 92 & $(50.6)$ & \\
\hline \multicolumn{19}{|l|}{ Age } \\
\hline $\begin{array}{l}50.0- \\
64.9\end{array}$ & 4 & 1 & $(25.0)$ & 1 & $(25.0)$ & 2 & $(50.0)$ & 5 & 2 & $(40.0)$ & 0 & $(0.0)$ & 3 & $(60.0)$ & 2 & 0 & $(0.0)$ & 1 \\
\hline $\begin{array}{l}65.0- \\
74.9\end{array}$ & 11 & 6 & $(54.5)$ & 2 & $(18.2)$ & 3 & (27.3) & 7 & 5 & (71.4) & 1 & (14.3) & 1 & (14.3) & 10 & 7 & $(70.0)$ & 2 \\
\hline $\begin{array}{l}75.0- \\
84.9\end{array}$ & 65 & 35 & (53.8) & 15 & $(23.1)$ & 15 & $(23.1)$ & 69 & 41 & (59.4) & 17 & $(24.6)$ & 11 & (15.9) & 69 & 43 & $(62.3)$ & $1<$ \\
\hline $85.0+$ & 136 & 64 & $(47.1)$ & 49 & $(36.0)$ & 23 & (16.9) & 128 & 60 & (46.9) & 42 & (32.8) & 26 & (20.3) & 101 & 42 & $(41.6)$ & $4 C$ \\
\hline \multicolumn{19}{|l|}{ Sex } \\
\hline Male & 65 & 29 & $(44.6)$ & 27 & $(41.5)$ & 9 & (13.8) & 64 & 36 & (56.3) & 13 & $(20.3)$ & 15 & $(23.4)$ & 53 & 32 & $(60.4)$ & $1<$ \\
\hline Female & 151 & 77 & $(51.0)$ & 40 & $(26.5)$ & 34 & $(22.5)$ & 145 & 72 & (49.7) & 47 & (32.4) & 26 & (17.9) & 129 & 60 & $(46.5)$ & $4 i$ \\
\hline
\end{tabular}

Considering all $\mathrm{MCl}$ and $\mathrm{AD}$ dementia participants as the denominator (Table 3, Fig. 3, and supplementary Figure B.2), the pooled percentage of mild $\mathrm{AD}$ dementia was $25.7 \%$, and the pooled percentage of the combined group of $\mathrm{MCl}$-progressive \& mild AD dementia was $45.2 \%$, consistent with results in each 
window. Comparing $\mathrm{MCl}$ by progression to $\mathrm{AD}$ dementia, the percentages of $\mathrm{MCl}$-not-progressive were higher than $\mathrm{MCl}$-progressive in the pooled estimate (29.5\% vs. $19.6 \%)$, in Window 2 (30.8\% vs. $19.7 \%)$ and Window 3 (36.2\% vs. $17.0 \%)$, but not in Window 1 (21.3\% vs. $22.0 \%)$. Stratifying by age, except for the youngest age group (50.0-64.9 y) which had only a limited number of cases, the relative proportion of MCl-progressive and MCl-not-progressive among all those with either $\mathrm{MCl}$ or $\mathrm{AD}$ dementia decreased with increasing age group. Meanwhile, the percentages of mild $\mathrm{AD}$ dementia and the combined group of $\mathrm{MCl}$ progressive \& mild AD dementia generally increased with increased age. Stratifying by sex, the percentages of MCl-not-progressive were higher in males than females (pooled estimates: $40.2 \%$ vs. $23.4 \%$ ). The pooled percentages of mild AD dementia and the combined group of $\mathrm{MCl}$-progressive \& mild $\mathrm{AD}$ dementia were higher in females (27.6\% and $48.1 \%)$ than in males $(22.3 \%$ and $40.2 \%)$.

Table 3

Percentages of $\mathrm{MCl}$ progression or mild $\mathrm{AD}$ in each time-window among all ca:

\begin{tabular}{|c|c|c|c|c|c|c|c|c|c|c|c|c|c|c|c|c|c|c|}
\hline \multirow[b]{3}{*}{ Overall } & \multicolumn{9}{|c|}{ Window 1 * } & \multicolumn{9}{|c|}{ Window $2^{*}$} \\
\hline & \multirow{2}{*}{$\begin{array}{l}\text { Total } \\
\text { AD \& } \\
\text { MCl } \\
381\end{array}$} & \multicolumn{2}{|c|}{$\begin{array}{l}\text { MCl-not- } \\
\text { progressive }\end{array}$} & \multicolumn{2}{|c|}{$\begin{array}{l}\mathrm{MCl} \\
\text { progressive }\end{array}$} & \multicolumn{2}{|c|}{ Mild AD } & \multicolumn{2}{|c|}{$\begin{array}{l}\text { MCl- } \\
\text { progressive } \\
\& \text { Mild AD }\end{array}$} & \multirow{2}{*}{$\begin{array}{l}\text { Total } \\
\mathrm{AD} \& \\
\mathrm{MCl} \\
422\end{array}$} & \multicolumn{2}{|c|}{$\begin{array}{l}\text { MCl-not- } \\
\text { progressive }\end{array}$} & \multicolumn{2}{|c|}{$\begin{array}{l}\mathrm{MCl} \\
\text { progressive }\end{array}$} & \multicolumn{2}{|c|}{ Mild AD } & \multicolumn{2}{|c|}{$\begin{array}{l}\text { MCl- } \\
\text { progressive } \\
\& \text { Mild AD }\end{array}$} \\
\hline & & 81 & (21.3) & 84 & $(22.0)$ & 106 & $(27.8)$ & 190 & (49.9) & & 130 & $(30.8)$ & 83 & (19.7) & 108 & $(25.6)$ & 191 & (45.3 \\
\hline \multicolumn{19}{|l|}{ Age } \\
\hline $\begin{array}{l}50.0- \\
64.9\end{array}$ & 11 & 7 & $(63.6)$ & 0 & $(0.0)$ & 1 & (9.1) & 1 & (9.1) & 18 & 11 & $(61.1)$ & 2 & (11.1) & 2 & (11.1) & 4 & $(22.2$ \\
\hline $\begin{array}{l}65.0- \\
74.9\end{array}$ & 37 & 14 & $(37.8)$ & 12 & $(32.4)$ & 6 & $(16.2)$ & 18 & $(48.6)$ & 49 & 27 & $(55.1)$ & 15 & $(30.6)$ & 5 & $(10.2)$ & 20 & (40.8 \\
\hline $\begin{array}{l}75.0- \\
84.9\end{array}$ & 125 & 28 & $(22.4)$ & 32 & $(25.6)$ & 35 & $(28.0)$ & 67 & $(53.6)$ & 157 & 51 & (32.5) & 37 & $(23.6)$ & 41 & $(26.1)$ & 78 & (49.7 \\
\hline $85.0+$ & 208 & 32 & (15.4) & 40 & (19.2) & 64 & $(30.8)$ & 104 & $(50.0)$ & 198 & 41 & $(20.7)$ & 29 & (14.6) & 60 & $(30.3)$ & 89 & (44.9 \\
\hline \multicolumn{19}{|l|}{$\begin{array}{l}\text { Sex, n } \\
(\%)\end{array}$} \\
\hline male & 133 & 43 & (32.3) & 25 & (18.8) & 29 & $(21.8)$ & 54 & $(40.6)$ & 161 & 67 & $(41.6)$ & 30 & (18.6) & 36 & $(22.4)$ & 66 & (41.0 \\
\hline female & 248 & 38 & (15.3) & 59 & $(23.8)$ & 77 & (31.0) & 136 & $(54.8)$ & 261 & 63 & $(24.1)$ & 53 & (20.3) & 72 & (27.6) & 125 & $(47.9$ \\
\hline
\end{tabular}

\section{Discussion}

The goal of this analysis was to estimate, among people living with AD, the proportion with mild, moderate, or severe dementia. We furthermore considered $\mathrm{MCl}$ as part of the spectrum of $\mathrm{AD}$, and explored differences by age and sex. To our knowledge, this is one of only two published epidemiological studies to provide information on the severity distribution of $A D$ in the general population. FHS is ideally suited for this analysis because of its systematic ascertainment of $\mathrm{MCl}$ and $\mathrm{AD}$ dementia with severity staging. Compared to $\mathrm{CHAP}[4]$, rather than using a single cognitive screening test for severity criterion, FHS used a consensus process that considered, when available, multiple cognitive tests and other sources of data to provide a more reliable and accurate ascertainment of severity. More precise confirmation of $\mathrm{MCl}$ due to $\mathrm{AD}$ was based on documented progression by capitalizing on the longitudinal data.

For the distribution of disease severity among AD dementia, FHS results are consistent with those reported by the Dementia UK 2007 report[6] and by CHAP[4]. Across all three studies, the percentage mild was higher than moderate, and the percentage moderate was higher than severe. Since the Dementia UK 2007 report was based on all dementia and not $A D$ dementia, the results in the present study are more appropriate to compare with those reported from the $\mathrm{CH} A P$ study[4]. The pooled estimates of mild, moderate, and severe AD dementia in the present analysis were $50.4 \%, 30.3 \%$, and $19.3 \%$, respectively, which are comparable to corresponding rates of $48 \%, 31 \%$, and $21 \%$ in the CHAP study. When restricting comparisons to the age-stratified analyses, results are consistent across the studies for some but not all age groups. For example, among ages 75-84 y with AD dementia, both studies reported that 59-60\% were mild and $~ 19-20 \%$ were severe. Similarly, among ages $85+y$, both studies reported that $~ 44-45 \%$ were mild; however, the proportion with severe was higher in CHAP ages $85+y(28 \%)$ than in FHS ages $85+(19 \%)$. This difference among the oldest age group may be explained by differences in study design, sample characteristics, and the smaller sample sizes within the age subgroups in FHS. Importantly, the number of FHS participants within age strata was small, which leads to unstable estimates by age. Regarding demographic differences across the two cohorts, participants of FHS were mainly Caucasian and had higher education levels compared to those in CHAP, which enrolled 10,000 community residents, $60 \%$ of whom were African-Americans, with a median of 12 years of education[17]. Also, the two studies had different sampling and research methods regarding cognitive evaluations. In CHAP, clinical evaluation for $A D$ was restricted to a stratified random sample of all participants, and the distribution of disease severity was based on weighted percentage data. In FHS, all participants who agreed to participate were administered comprehensive NP test protocol, although only a subset of participants are prioritized to be dementia reviewed based on performance criteria and/or referrals[11, 12]. The ideal would have been to have all participants reviewed in the community-based study regardless of cognitive status. Although neither FHS nor CHAP fulfilled this ideal, the FHS methods did identify cognitively impaired participants as much as was feasibly possible in a community-based cohort, which allowed us to directly calculate the distribution of severity, based on actual cases within a specified period. Lastly, in CHAP, a MMSE cut-off score was used for determining severity. In FHS, the diagnosis and judgment of disease severity were made by consensus review with all available data, which is more accurate than using MMSE only. 
Indeed, both CHAP and FHS highlight the challenges of operationalizing criteria for cognitive and functional impairment when conducting population-based studies $[2,18]$. Despite published criteria covering subtypes and definitions, there is no definitive best method to measure specific domains, and no consensus on determining the diagnosis psychometrically by NP test scores or by consensus review[19]. The prevalence of $\mathrm{MCl}$ ranges from 3-42\% in observational epidemiological studies[20]. Heterogeneity in $\mathrm{MCl}$ incidence estimates was also reported in a recent meta-analysis[21]. A relevant concern are the rates of $\mathrm{MCl}$ reported to revert to normal cognition in community-based studies, which vary from 30-50\% with 2-5 years of follow-up[22]. Biomarker data would help to confirm AD pathology, but currently AD biomarkers are difficult to collect in large population-based studies. Thus, prior cross-sectional studies have limitations in their determination of $\mathrm{MCl}$ and whether it is likely due to $\mathrm{AD}$. Despite lack of AD biomarkers in FHS, a strength of this analysis is the use of longitudinal data that documented progression to $\mathrm{AD}$ dementia to make the ascertainment of $\mathrm{MCl}$ possibly due to $\mathrm{AD}$.

Our analysis focused on $\mathrm{MCl}$ due to $\mathrm{AD}$ and mild $\mathrm{AD}$ dementia, more so than moderate or severe, as current priorities in $A D$ research and drug development focus on the earlier stages. Of note, moderate to severe AD dementia, which is substantially burdensome to patients and society, was also common, accounting for half of all $A D$ dementia. Among females with $\mathrm{MCl}$ or $A D$, the percentages of mild $A D$ and the combined group of $M C l$-progressive \& mild $A D$ were slightly higher than those among males. However, additional research is needed to determine whether the observed uneven distribution was due to underlying pathophysiological sex difference, the disproportionate sample size with more females, or other imbalanced distribution of cognitive risk factors. The CHAP study did not report sex-stratified analyses[4].

Limitations of this analysis relate primarily to the largely homogenous study population and lack of AD biomarker confirmation. First, the FHS cohort participants were almost homogenously Caucasians and residents of a single city in MA. It is worthwhile to conduct further investigations in more racially and geographically diverse populations. Second, although FHS is a longitudinal study, and our analysis included participants from both the original and newer cohorts, the study population over the three time windows would not be expected to be as dynamic as that of sampling participants from different geographic areas. It is possible that cases who had more severe AD were more likely to be lost to follow up, which could lead to over-estimating the percentages in milder stages, particularly in later time windows. However, FHS had rigorous methods to maintain contact and continue follow-up regardless of participants' dementia severity, relocation to other geographic locations, institutionalization, or death, by doing full review of electronic health records for deceased participants. Indeed, we did not observe a higher proportion of mild dementia in the later time window compared to the earlier window. Lastly, the study lacked $\mathrm{AD}$ biomarker confirmation (e.g., amyloid, tau, neurodegeneration)[23], which would have increased the accuracy of case ascertainment.

\section{Conclusion}

In this epidemiological study, approximately half of prevalent AD dementia cases were of mild severity, whereas approximately one-fifth were severe. When the analysis further considered prevalent $\mathrm{MCl}$ as well as $\mathrm{AD}$ dementia, approximately $45 \%$ of all cognitively impaired or $A D$-demented participants had early $A D$ (i.e., $\mathrm{MCl}$ that would be observed to progress to $A D$ dementia or mild $A D$ ). Early intervention in $\mathrm{MCl}$ or the mild stage of $A D$ dementia has been the primary focus for $A D$ research and drug development in recent years. Meanwhile, studies providing prevalence data for $A D$ have largely neglected characterizing the severity of $A D$ cases. This disconnect hampers the ability to plan clinical trials, observational research, and policy-making regarding $A D$ therapies targeted at particular stages of disease. Accordingly, our results help fill a data gap on the severity distribution of the symptomatic AD continuum and serve to inform the design of future research studies and optimal resource allocation for policy-making.

\section{Abbreviations}

AD: Alzheimer's disease; MCl: Mild cognitive impairment; FHS:Framingham Heart Study; CHAP: The Chicago Health and Aging Project; MMSE: Mini-Mental State Examination; NP: neuropsychological; CDR: Clinical Dementia Rating; ApoE e4: apolipoprotein- E e4; GEE: generalized estimating equation; Cl: confidence interval

\section{Declarations}

\section{Ethics approval and consent to participate}

The Boston University Medical Campus and Boston Medical Center Institutional Review Board (BUMC/BMC IRB) approved the study procedures and protocols. Written informed consent was obtained from all participants.

Consent for publication: Not applicable.

\section{Author Contributions}

Concept and design: All authors.

Acquisition, analysis, or interpretation of data: All authors.

Drafting of the manuscript: Jing Yuan, Nancy Maserejian, Joseph Massaro

Critical revision of the manuscript for important intellectual content: All authors

Statistical analysis: Yulin Liu, Joseph Massaro

Administrative, technical, or material support: Jing Yuan, Yulin Liu, Joseph Massaro, Sherral Devine, Rhoda Au 
Supervision: Rhoda Au, Joseph Massaro

Acknowledgments: We thank the Framingham Heart Study (FHS) participants for their decades of dedication and the FHS staff for their hard work in collecting and preparing the data.

Competing interests: Nancy Maserejian and Cai Gillis are employees and shareholders of Biogen. Rhoda Au is a scientific advisor to Signant Health. There is no declaration from other authors.

Funding Sources: This work was supported by the Framingham Heart Study's National Heart, Lung, and Blood Institute contract (N01-HC-25195; HHSN268201500001I), and NIH grants from the National Institute on Aging (AG008122, AG016495, AG033040, AG054156), and Pfizer; Analytic support was provided by Biogen.

Support for Jing Yuan was also provided by the Chinese Academy of Medical Sciences Innovation Fund for Medical Sciences (2016I2M1004); National Key Cooperation between the BRICS Program of China (No.2017YFE0100500)

Availability of data and materials:

External Data Repositories: FHS research data is stored in the following external repositories and may be accessed by application to those external repositories. These repositories are managed and administered independently of the Framingham Heart Study. There are no fees charged for data accessed through dbGaP or BioLINCC.

Internal FHS Repository: Investigators seeking FHS data that is not available through dbGaP or BioLINCC (see above) or seeking biological specimens may submit a proposal through the FHS web-based research application at: https://framinghamheartstudy.org/fhs-for-researchers/research-application/.

\section{References}

1. Sperling RA, Aisen PS, Beckett LA, Bennett DA, Craft S, Fagan AM, Iwatsubo T, Jack CR, Jr., Kaye J, Montine TJ et al: Toward defining the preclinical stages of Alzheimer's disease: recommendations from the National Institute on Aging-Alzheimer's Association workgroups on diagnostic guidelines for Alzheimer's disease. Alzheimer's \& dementia : the journal of the Alzheimer's Association 2011, 7(3):280-292.

2. Albert MS, DeKosky ST, Dickson D, Dubois B, Feldman HH, Fox NC, Gamst A, Holtzman DM, Jagust WJ, Petersen RC et al: The diagnosis of mild cognitive impairment due to Alzheimer's disease: recommendations from the National Institute on Aging-Alzheimer's Association workgroups on diagnostic guidelines for Alzheimer's disease. Alzheimer's \& dementia : the journal of the Alzheimer's Association 2011, 7(3):270-279.

3. McKhann GM, Knopman DS, Chertkow H, Hyman BT, Jack CR, Jr., Kawas CH, Klunk WE, Koroshetz WJ, Manly JJ, Mayeux R et al: The diagnosis of dementia due to Alzheimer's disease: recommendations from the National Institute on Aging-Alzheimer's Association workgroups on diagnostic guidelines for Alzheimer's disease. Alzheimer's \& dementia : the journal of the Alzheimer's Association 2011, 7(3):263-269.

4. Hebert LE, Scherr PA, Bienias JL, Bennett DA, Evans DA: Alzheimer disease in the US population: prevalence estimates using the 2000 census. Arch Neurol 2003, 60(8):1119-1122.

5. Folstein MF, Folstein SE, McHugh PR: "Mini-mental state". A practical method for grading the cognitive state of patients for the clinician. Journal of psychiatric research 1975, 12(3):189-198.

6. Society As: Dementia UK: The full report: Alzheimer's Society; 2007.

7. Prince M, Knapp M, Guerchet M, McCrone P, Prina M, Comas-Herrera A, Wittenberg R, Adelaja B, Hu B, King D: Dementia UK: -overview. 2014.

8. Mahmood SS, Levy D, Vasan RS, Wang TJ: The Framingham Heart Study and the epidemiology of cardiovascular disease: a historical perspective. Lancet (London, England) 2014, 383(9921):999-1008.

9. Tsao CW, Vasan RS: Cohort Profile: The Framingham Heart Study (FHS): overview of milestones in cardiovascular epidemiology. International journal of epidemiology 2015, 44(6):1800-1813.

10. Splansky GL, Corey D, Yang Q, Atwood LD, Cupples LA, Benjamin EJ, D'Agostino RB, Fox CS, Larson MG, Murabito JM et al: The Third Generation Cohort of the National Heart, Lung, and Blood Institute's Framingham Heart Study: Design, Recruitment, and Initial Examination. American journal of epidemiology 2007, 165(11):1328-1335.

11. Seshadri S, Wolf PA, Beiser A, Au R, McNulty K, White R, D'Agostino RB: Lifetime risk of dementia and Alzheimer's disease. The impact of mortality on risk estimates in the Framingham Study. Neurology 1997, 49(6):1498-1504.

12. Au R, Piers RJ, Devine S: How technology is reshaping cognitive assessment: Lessons from the Framingham Heart Study. Neuropsychology 2017, 31(8):846-861.

13. Association AP: Diagnostic and statistical manual of mental disorders (DSMIV). Washington, D.C.American Psychiatric Association 1994.

14. McKhann G, Drachman D, Folstein M, Katzman R, Price D, Stadlan EM: Clinical diagnosis of Alzheimer's disease: report of the NINCDS-ADRDA Work Group under the auspices of Department of Health and Human Services Task Force on Alzheimer's Disease. Neurology 1984, 34(7):939-944.

15. Hughes CP, Berg L, Danziger WL, Coben LA, Martin RL: A new clinical scale for the staging of dementia. Br J Psychiatry 1982, 140:566-572.

16. Kawas C, Gray S, Brookmeyer R, Fozard J, Zonderman A: Age-specific incidence rates of Alzheimer's disease: the Baltimore Longitudinal Study of Aging. Neurology 2000, 54(11):2072-2077. 
17. Bienias JL, Beckett LA, Bennett DA, Wilson RS, Evans DA: Design of the Chicago health and aging project (CHAP). Journal of Alzheimer's Disease 2003, 5(5):349-355.

18. Winblad B, Palmer K, Kivipelto M, Jelic V, Fratiglioni L, Wahlund LO, Nordberg A, Backman L, Albert M, Almkvist O et al: Mild cognitive impaiment-beyond controversies, towards a consensus: report of the International Working Group on Mild Cognitive Impairment. J Intern Med 2004, 256(3):240-246.

19. Petersen RC, Morris JC: Mild cognitive impairment as a clinical entity and treatment target. Arch Neurol 2005, 62(7):1160-1163; discussion 1167.

20. Ward A, Arrighi HM, Michels S, Cedarbaum JM: Mild cognitive impairment: disparity of incidence and prevalence estimates. Alzheimer's \& dementia : the journal of the Alzheimer's Association 2012, 8(1):14-21.

21. Gillis $C$, Mirzaei F, Potashman M, Ikram MA, Maserejian N: The incidence of mild cognitive impairment: A systematic review and data synthesis. Alzheimer's \& dementia (Amsterdam, Netherlands) 2019, 11:248-256.

22. Pandya SY, Clem MA, Silva LM, Woon FL: Does mild cognitive impairment always lead to dementia? A review. Journal of the neurological sciences 2016, 369:57-62.

23. Jack CR, Jr., Bennett DA, Blennow K, Carrillo MC, Feldman HH, Frisoni GB, Hampel H, Jagust WJ, Johnson KA, Knopman DS et al: AT/N: An unbiased descriptive classification scheme for Alzheimer disease biomarkers. Neurology 2016, 87(5):539-547.

\section{Figures}

A Time-window $1(2004-2005)$

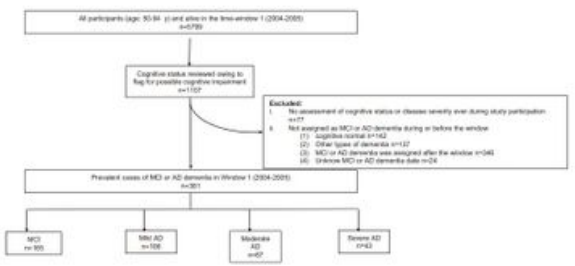

B Time-window $2(2006-2007)$

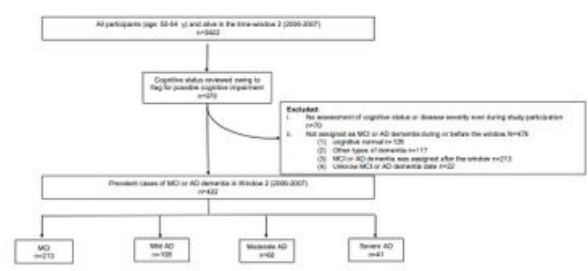

C Time-window $3(2008-2009)$

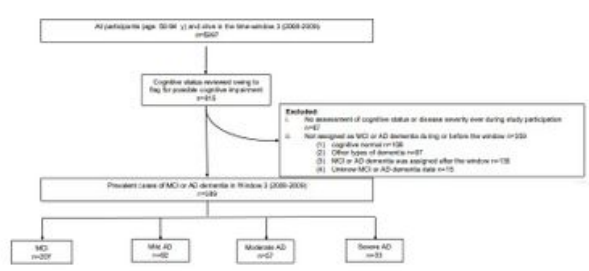

Figure 1

Flowchart of sample selection Legend Participants aged 50-94 y with a cognitive assessment and a consensus determination of disease severity of $\mathrm{MCl}$ and $A D$ in three time-windows.

60

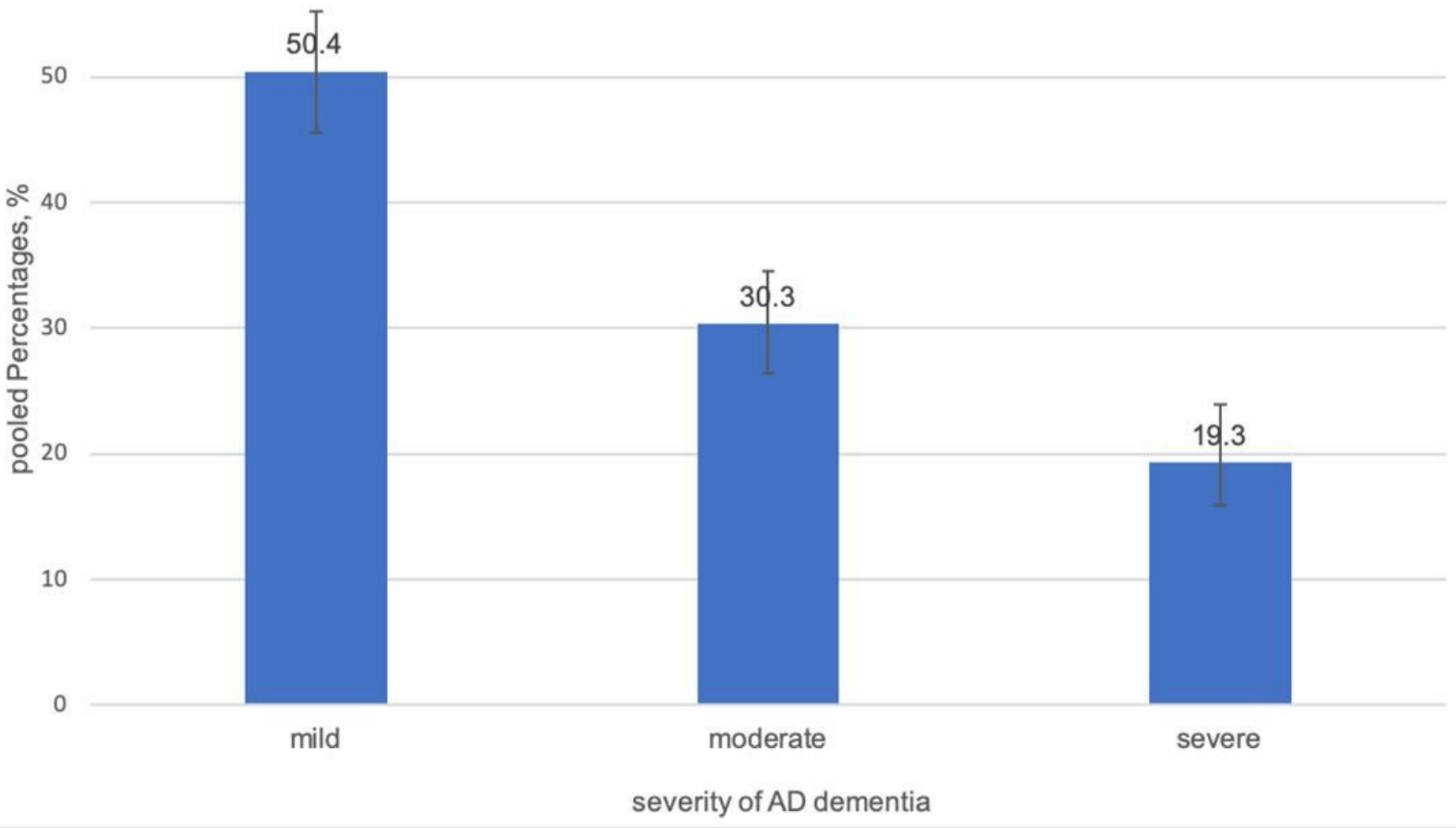


Figure 2

Pooled percentages of $A D$ dementia clinical syndrome by disease severity among participants with $A D$ dementia. Legend Pooled percentages of $A D$ dementia by disease severity (mild, moderate, and severe) in three time-windows were illustrated among participants with AD dementia. The $95 \%$ confidence intervals were showed by error bars.

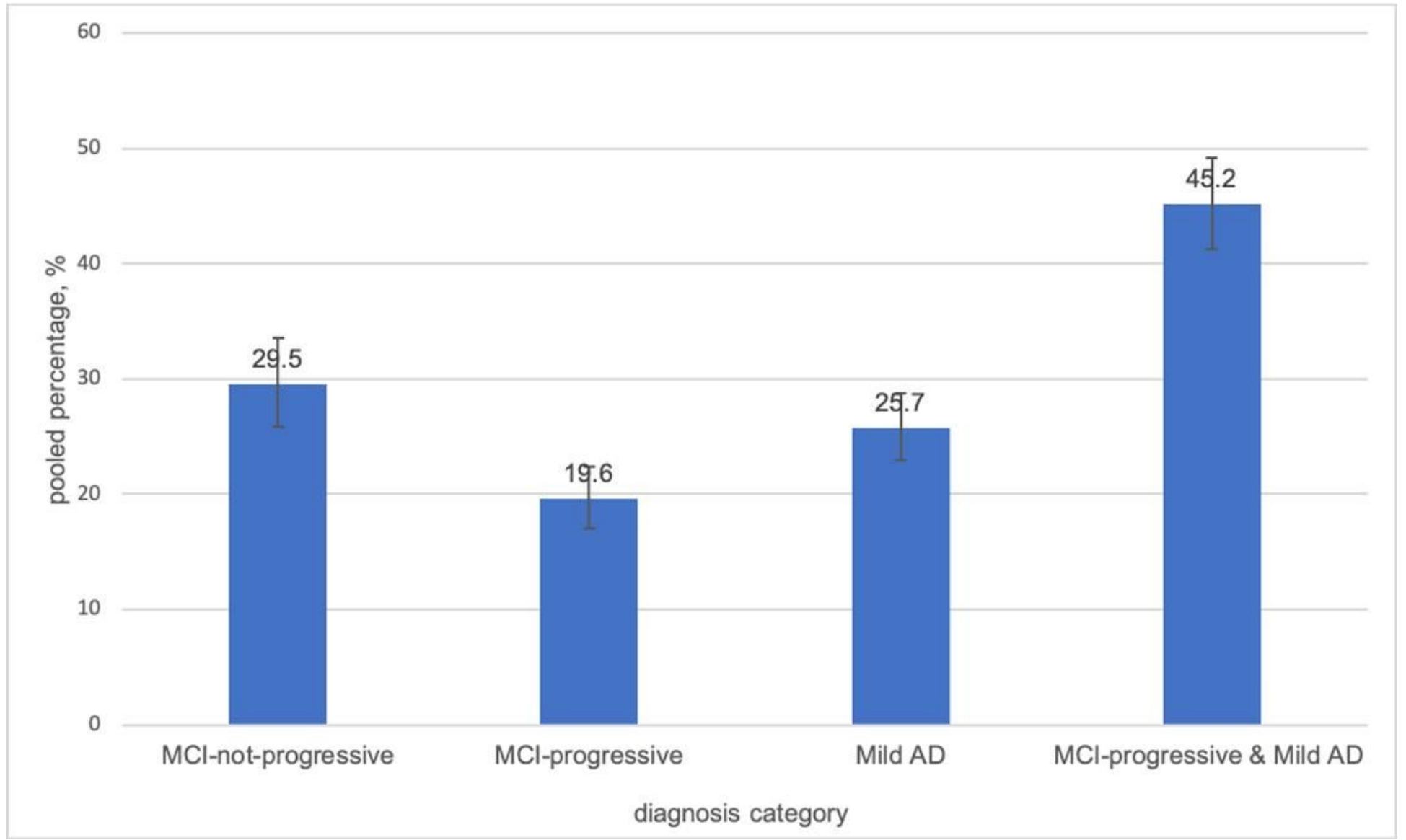

Figure 3

Pooled percentages of $\mathrm{MCl}$ progression status or mild $\mathrm{AD}$ among all cases Legend Pooled percentages of $\mathrm{MCl}$-not-progressive, $\mathrm{MCl}$-progressive, mild $\mathrm{AD}$, $\mathrm{MCl}$ progressive \& mild AD in three time-windows were illustrated among participants with $A D$ dementia or $\mathrm{MCl}$. The $95 \%$ confidence intervals were showed by error bars.

\section{Supplementary Files}

This is a list of supplementary files associated with this preprint. Click to download.

- SupplementaryFigureB.2byJingYuanetal.png

- SupplementaryFigureB.1byJingYuanetal.pdf

- AppendixBsupplementaryFiguresB.1B.2titleandlegend.docx

- AppendixATableA.2.docx

- AppendixATableA.1.docx 